\title{
Pharmacological inhibition of diacylglycerol acyltransferase 1 reduces body weight gain, hyperlipidemia, and hepatic steatosis in $\mathrm{db} / \mathrm{db}$ mice
}

\author{
Xiao-dong ZHANG ${ }^{1}$, Jian-wei YAN ${ }^{1}$, Gui-rui YAN ${ }^{1}$, Xiao-yun SUN ${ }^{1}$, Jun $\mathrm{JI}^{1}$, Yi-ming $\mathrm{LI}^{2}$, You-hong HU ${ }^{1, *}$, He-yao WANG ${ }^{1, *}$ \\ ${ }^{1}$ Shanghai Institute of Materia Medica, Chinese Academy of Sciences, Shanghai 201203, China; ${ }^{2}$ School of Pharmacy, Shanghai Uni- \\ versity of Traditional Chinese Medicine, Shanghai 201203, China
}

Aim: To test whether pharmacological inhibition of Diacylglycerol acyltransferase 1 (DGAT1) by a small-molecule inhibitor H128 can improve metabolism disorders in leptin receptor-deficient $d b / d b$ mice.

Methods: To investigate the effect of $\mathrm{H} 128$ on intestinal fat absorption, $d b / d b$ mice were acutely given a bolus of corn oil by gavage. The mice were further orally administered $\mathrm{H} 128$ ( 3 and $10 \mathrm{mg} / \mathrm{kg}$ ) for 5 weeks. Blood glucose, lipids, insulin, ALT, and AST as well as hepatic triglycerides were measured. The insulin tolerance test was performed to evaluate insulin sensitivity. The expression of genes involved in fatty acid oxidation was detected by RT-PCR.

Results: Oral administration of $\mathrm{H} 128$ (10 mg/kg) acutely inhibited intestinal fat absorption following a lipid challenge in $\mathrm{db} / \mathrm{db}$ mice. Chronic treatment with $\mathrm{H} 128$ significantly inhibited body weight gain, decreased food intake, and induced a pronounced reduction of serum triglycerides. In addition, $\mathrm{H} 128$ treatment markedly ameliorated hepatic steatosis, characterized by decreased liver weight, lipid droplets, and triglyceride content as well as serum ALT and AST levels. Furthermore, H128 treatment increased the expression of the CPT1 and PPAR $\alpha$ genes in liver, suggesting that $\mathrm{H} 128$ enhanced fatty acid oxidation in $d b / d b$ mice. However, neither blood glucose nor insulin tolerance was affected by $\mathrm{H} 128$ treatment throughout the 5-week experimental period.

Conclusion: DGAT1 may be an effective therapeutic target for the treatment of obesity, hyperlipidemia and hepatic steatosis.

Keywords: diabetes; hepatic steatosis; obesity; hyperlipidemia; small-molecule inhibitor; H128; diacylglycerol acyltransferase 1; $d b / d b$ mice; CPT1 gene; PPAR $\alpha$ gene

Acta Pharmacologica Sinica (2010) 31: 1470-1477; doi: 10.1038/aps.2010.104

\section{Introduction}

Recently, the prevalence of obesity has increased dramatically worldwide along with obesity-related metabolic disorders, such as hyperlipidemia, hepatic steatosis and type 2 diabetes $^{[1,2]}$. The primary defect in obesity is the excessive accumulation of triglycerides in the blood, white adipose tissue (WAT), liver, and other tissues ${ }^{[3]}$. Inhibition of triglyceride synthesis may be a feasible strategy for the treatment of obesity and its related medical consequences ${ }^{[4,5]}$.

The final and only committed step in mammalian triglyceride synthesis is catalyzed by acyl CoA:diacylglycerol acyltransferase (DGAT) enzymes, which convert diacylglycerol and fatty acyl-CoA into triglycerides ${ }^{[6]}$. Mammals have

\footnotetext{
* To whom correspondence should be addressed.

E-mail hywang@mail.shcnc.ac.cn (He-yao WANG); yhhu@mail.shcnc.ac.cn (You-hong HU)

Received 2010-03-21 Accepted 2010-06-28
}

two DGAT enzymes (DGAT1 and DGAT2), which share no sequence homology ${ }^{[7,8]}$. Both enzymes are ubiquitously expressed in mammalian tissues and are highly expressed in adipose tissue, liver and intestine, where triglyceride synthesis is most active ${ }^{[9]}$. DGAT2-deficient $\left(\operatorname{Dgat}^{-/-}\right)$mice die early in the postnatal period due to severe triglyceride depletion, implying that DGAT2 function is crucial for survival ${ }^{[10]}$.

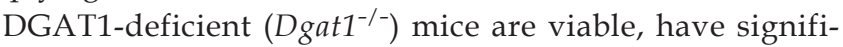
cantly reduced tissue triglycerides, and are resistant to highfat diet-induced body weight gain through increased energy expenditure rather than decreased food intake ${ }^{[11-13]}$. Dgat $1^{-/-}$ mice are also protected from insulin resistance caused by a high-fat diet or by genetic crosses onto the Agouti yellow (AY/a) background $^{[12-14]}$. In addition, knockdown of DGAT1 expression with antisense oligonucleotides protects against hepatic steatosis induced by a high-fat diet ${ }^{[15]}$. Thus, DGAT1 may represent a novel therapeutic target for obesity, diabetes, and hepatic steatosis ${ }^{[4,16,17]}$. 
Recent reports show that pharmacologic inhibition of DGAT1 by small molecules suppresses high-fat diet-induced body weight gain in diet-induced obese (DIO) mice ${ }^{[18,19]}$. However, to the best of our knowledge, no studies have examined the effects of small-molecule DGAT1 inhibitors on glucose metabolism in animal models. H128 (Figure 1A) is a potent DGAT1 inhibitor with an $\mathrm{IC}_{50}$ value of $98 \mathrm{nmol} / \mathrm{L}$ against human DGAT1 $1^{[19]}$. In this study, we sought to determine whether H128 could improve glucose metabolism in leptin receptor-deficient $d b / d b$ mice, which spontaneously develop obesity and diabetes. We also evaluated the effects of H128 on body weight, blood lipids, and hepatic steatosis in $d b / d b$ mice.

\section{Materials and methods Compound}

H128 was synthesized in the Shanghai Institute of Materia Medica, Chinese Academy of Sciences. H128 was prepared in $0.5 \%$ Tween- 80 solution in water for in vivo studies.

\section{Animals and experimental protocols}

Male C57BL/KsJ-Lep ${ }^{\mathrm{db}}(d b / d b)$ and their lean littermates, obtained from Jackson Laboratories (Bar Harbor, Maine, USA), were maintained in a 12:12 light-dark cycle with ad libitum access to water and a normal chow diet. The $d b / d b$ mice at 10 weeks of age were divided into three groups ( $n=5-6 /$ group) on the basis of fasting blood glucose level and body weight. The $d b / d b$ mice were gavaged once daily with vehicle $(0.5 \%$ Tween-80) or H128 (3 mg/ $\mathrm{kg}$ and $10 \mathrm{mg} / \mathrm{kg}$ ) for 5 weeks. The lean mice were also treated with vehicle in an identical manner. Blood glucose was monitored in tail vein blood using a glucometer (One-Touch Ultra, Lifescan, Milpitas, USA) every week after $6 \mathrm{~h}$ fasting. Body weight and food intake were measured regularly. At the end of the experimental period, mice were fasted for $12 \mathrm{~h}$, after which serum and liver samples were collected. A section of liver was processed for histopathologic studies, and the remainder was snap-frozen in liquid nitrogen and stored at $-80^{\circ} \mathrm{C}$ for later analysis. All animal procedures were approved by the Animal Care and Use Committee of the Shanghai Institute of Materia Medica, Chinese Academy of Sciences.

\section{Acute lipid challenge test}

Male $d b / d b$ mice at 8 weeks of age, previously maintained on a chow diet, were fasted for $16 \mathrm{~h}$. Animals were given H128 or vehicle by oral gavage and, $1 \mathrm{~h}$ later, given a bolus of corn oil $(5 \mathrm{~mL} / \mathrm{kg})$. After an additional $1 \mathrm{~h}$, blood samples were collected from the ophthalmic venous plexus. Serum triglyceride level was determined using a commercially available colorimetric kit (Rongsheng, Shanghai, China).

\section{Intraperitoneal insulin tolerance test}

After 4 weeks receiving vehicle or $\mathrm{H} 128$, mice were fasted for $6 \mathrm{~h}$, followed by intraperitoneal administration of insulin (1 unit $/ \mathrm{kg}$ ). Blood glucose was measured from the tail vein using the same glucometer at 0 (prior to insulin administration), 30, 60, 90, and 120 min after insulin administration.

\section{Biochemical measurements}

Serum triglyceride and cholesterol levels were measured using commercial enzyme assay kits (Rongsheng, Shanghai, China). Serum insulin was assayed with an insulin ELISA kit (Linco Research, MO, USA). The activities of aspartate aminotransferase (AST) and alanine aminotransferase (ALT) in serum were determined by commercial kits (Rongsheng, Shanghai, China)

To measure liver triglyceride content, liver triglycerides were extracted with ethanol by a procedure modified from Cool et al ${ }^{[20]}$. Briefly, liver samples were homogenized in 30 volumes of ethanol, then vortexed and centrifuged at $15000 \times g$ for $10 \mathrm{~min}$ at room temperature. The supernatant was used to measure liver triglyceride content as described above.

\section{Histological analysis}

Liver samples were fixed in $10 \%$ buffered formalin and embedded in paraffin wax. After dehydration, the sections were stained with hematoxylin \& eosin. To visualize neutral lipids, liver samples were frozen in Tissue-Tek OCT compound (Sakura Finetek USA Inc, CA, USA) and sections were stained with Oil-Red O. Images of the histological sections were analyzed for hepatic steatosis.

\section{Gene expression analysis}

Total RNA was extracted from frozen liver samples (50 mg) using an RNeasy Lipid Tissue Mini Kit (Qiagen, Tokyo, Japan). For gene expression analysis, the cDNA was synthesized from total RNA using M-MLV reverse transcriptase (Invitrogen Life Technologies, California, USA). Semi-quantitative real-time PCR was performed using SYBR ${ }^{\circledR}$ Premix Ex Taq ${ }^{\mathrm{TM}}$ II (Takara, Dalian, China) on the 7500 Fast Real-Time PCR System (Applied Biosystems, Foster City, USA). All of the primers used are listed in Table 1 . The mRNA levels were normalized relative to the amount of $\beta$-actin mRNA and are presented as arbitrary units.

\section{Statistical analysis}

All data are expressed as the mean \pm SEM. The comparison of different groups was assessed by two-tailed unpaired Student's $t$ test. Differences were considered statistically significant at $P<0.05$.

\section{Results}

H128 acutely inhibits intestinal triglyceride absorption in $\mathrm{db} / \mathrm{db}$ mice

To investigate the effect of inhibition of DGAT1 on intestinal triglyceride absorption in $d b / d b$ mice, H128 was evaluated in an acute lipid challenge model by measuring serum triglyceride level following a bolus of corn oil. One hour after a lipid challenge, serum triglycerides were increased by $54 \%(0.94 \pm 0.07$ vs $1.44 \pm 0.05, P<0.01)$ in $d b / d b$ mice (Figure 1B). However, when mice were pretreated with $10 \mathrm{mg} / \mathrm{kg}$ of H128 $1 \mathrm{~h}$ followed by a lipid challenge, serum triglycerides remained close to the original level (Figure 1B). Thus, H128 can acutely inhibit intestinal triglyceride absorption following 
Table 1. Primers used in gene expression analysis.

\begin{tabular}{lll}
\hline Probe & \multicolumn{1}{c}{ Forward } & Reverse \\
\hline ACC1 & CTTCCTGACAAACGAGTCTGG & CTGCCGAAACATCTCTGGGA \\
CPT1a & CTTCCATGACTCGGCTCTTC & AGCTTGAACCTCTGCTCTGC \\
PPAR $\alpha$ & TTGCTGTGGAGATCGGCCT & GGATGGTTGCTCTGCAGGTG \\
PPARy & TTTTCAAGGGGCCAGTTTC & AATCCTTGGCCCTCTGAGAT \\
SCD-1 & CAAGCTGGAGTACGTCTGGA & CAGAGCGCTGGTCATGTAGT \\
SREBP1c & TGGAGACATCGCAAACAAGC & TGGTAGACAACAGCCGCATC \\
B-actin & CACGATGGAGGGGCGGACTCATC & CTAAAGACCTCTATGCCAACACAGT \\
\hline
\end{tabular}<smiles>O=C(Nc1ccccc1)Nc1ccc(-c2ccc(C(=O)C3CCCC3C(=O)O)cc2)cc1</smiles>

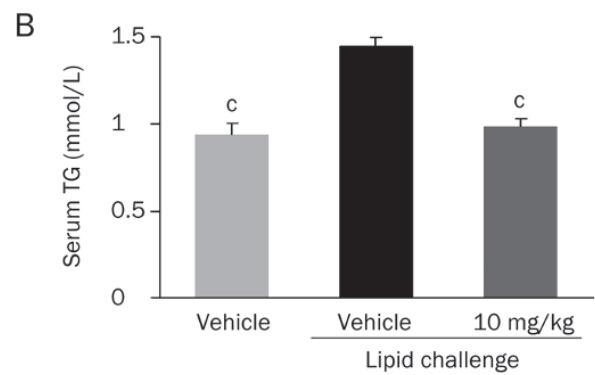

Figure 1. Structure of $\mathrm{H} 128$ and serum triglyceride level after an acute lipid challenge in $d b / d b$ mice. (A) Structure of H128. (B) Serum triglyceride (TG) level. The acute lipid challenge test was performed as described in Materials and Methods. The data are expressed as the mean \pm SEM. $n=5 .{ }^{c} P<0.01$ vs vehicle group.

a lipid challenge in $d b / d b$ mice.

\section{Effects of H128 on body weight gain and food intake in $d b / d b$ mice}

Next, we investigated the chronic effects of H128 on body weight gain and food intake in $d b / d b$ mice. H128 treatment at $10 \mathrm{mg} / \mathrm{kg}$ for 5 weeks markedly suppressed body weight gain by about $50 \%(11.32 \pm 1.39$ vs $5.74 \pm 0.53, P<0.05)$ relative to the vehicle-treated group (Figure $2 \mathrm{~B}$ ); this reduction began at the fourth week of H128 treatment (Figure 2A). Additionally, treatment with $3 \mathrm{mg} / \mathrm{kg} \mathrm{H} 128$ elicited a slight decrease (about $30 \%$ ) in body weight gain at the end of the experiment (Figure 2B). At both doses of $3 \mathrm{mg} / \mathrm{kg}$ and $10 \mathrm{mg} / \mathrm{kg}$, H128 treatment modestly reduced food intake as compared with the vehicletreated mice throughout the 5-week experimental period (Figure 2C). Food intake in H128-treated mice was decreased by $7.8 \%(5.85 \pm 0.06$ vs $5.39 \pm 0.09, P<0.05)$ by $3 \mathrm{mg} / \mathrm{kg}$ and by $6.8 \%$
(5.85 \pm 0.06 vs $5.45 \pm 0.11, P<0.05)$ by $10 \mathrm{mg} / \mathrm{kg} \mathrm{H} 128$ (Figure 2D).

Effects of $\mathrm{H} 128$ on blood lipids and glucose metabolism in $d b /$ $d b$ mice

$d b / d b$ mice usually serve as a genetic animal model of metabolic disorders with significant obesity, hyperlipidemia, and fasting hyperglycemia. As shown in Figure $3, d b / d b$ mice displayed higher levels of triglycerides, cholesterol, glucose, and insulin in the blood compared with lean mice. Five weeks of $\mathrm{H} 128$ treatment at doses of 3 and $10 \mathrm{mg} / \mathrm{kg}$ produced pronounced reductions of serum triglyceride levels in $d b / d b$ mice (Figure 3A). Although no significant difference was found in serum cholesterol, there was a trend towards decreased cholesterol in $d b / d b$ mice treated by H128 (Figure 3B).

To evaluate whether H128 treatment also improves glucose homeostasis in $d b / d b$ mice, fasting blood glucose level was measured during the experimental period. H128 did not affect blood glucose level after 1, 2, or 4 weeks of treatment (Figure 3D). We further conducted an intraperitoneal insulin tolerance test to evaluate the effect of H128 treatment on insulin sensitivity. The glucose levels at different times were similar between vehicle- and H128-treated $d b / d b$ mice (Figure 3E). Although H128 treatment significantly decreased serum insulin level (Figure 3C), neither glucose homeostasis nor insulin resistance in $d b / d b$ mice was improved by $\mathrm{H} 128$ treatment.

\section{H128 improved hep atic steatosis in $d b / d b$ mice}

Because DGAT1 catalyzes the final step in triglyceride synthesis, decreasing DGAT1 activity is assumed to reduce hepatic steatosis ${ }^{[15]}$. Compared with the lean mice, the $d b / d b$ mice (vehicle-treated) exhibited severe hepatic steatosis characterized by numerous "foamy" cells (hematoxylin \& eosin staining) and lipid droplets (Oil-Red O staining) (Figure 4A). After 5 weeks of H128 treatment at the dose of $10 \mathrm{mg} / \mathrm{kg}$, the "foamy" cells and lipid droplets were decreased (Figure 4A). Biochemical analysis of triglyceride content in liver further confirmed the histological changes (Figure 4B). H128 treatment at $10 \mathrm{mg} / \mathrm{kg}$ decreased hepatic triglyceride content by $25 \%(197.08 \pm 12.94$ vs $148.22 \pm 7.51, P<0.05)$. In addition, a corresponding decrease in liver weight was observed in H128treated $d b / d b$ mice compared with the vehicle group $(2.55 \pm 0.12$ vs $2.04 \pm 0.02, P<0.05$ ) (Figure $4 \mathrm{C}$ ). Liver enzymes ALT and AST were also measured in serum as an indication of liver 

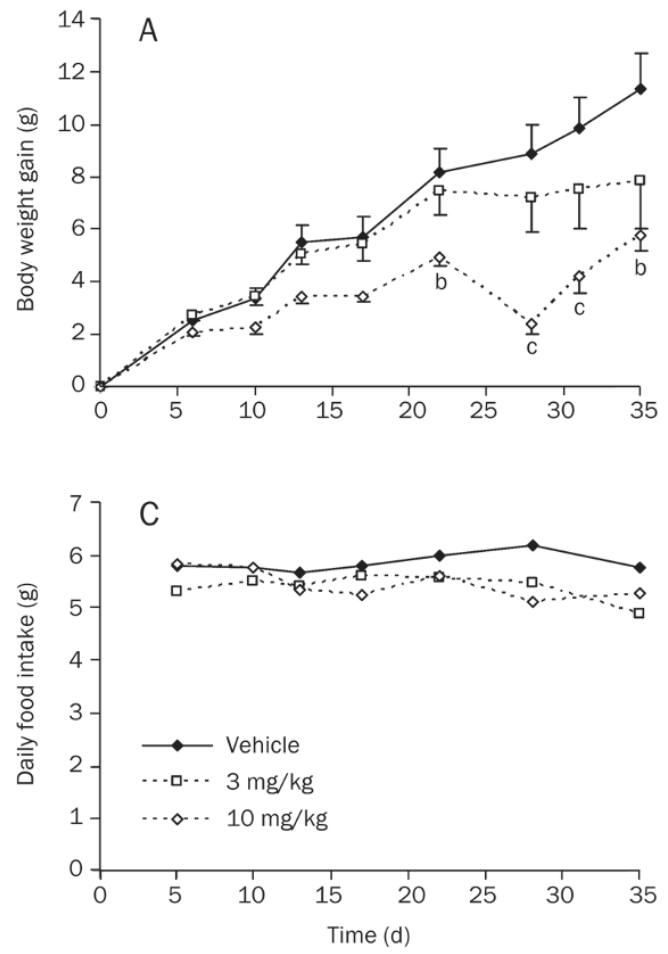

B

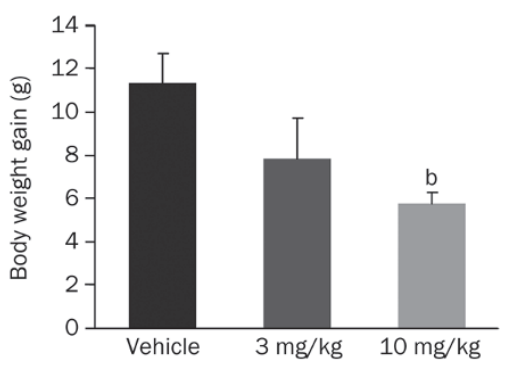

D

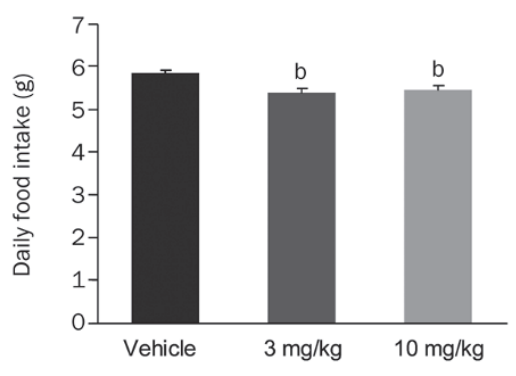

Figure 2. H128 treatment decreases body weight gain and food intake in $d b / d b$ mice. Beginning at 10 weeks of age, male mice were orally gavaged with vehicle $(0.5 \%$ Tween- 80$)$ or 3 or 10 $\mathrm{mg} / \mathrm{kg}$ of $\mathrm{H} 128$ for 5 weeks. (A) Body weight gain throughout the 5 -week experimental period. (B) Body weight gain at the end of the experimental period. (C) Daily food intake and (D) average daily food intake throughout the 5-week experimental period. All data are expressed as the mean \pm SEM. $n=5-6 . \quad{ }^{b} P<0.05,{ }^{c} P<0.01$ vs vehicle group.
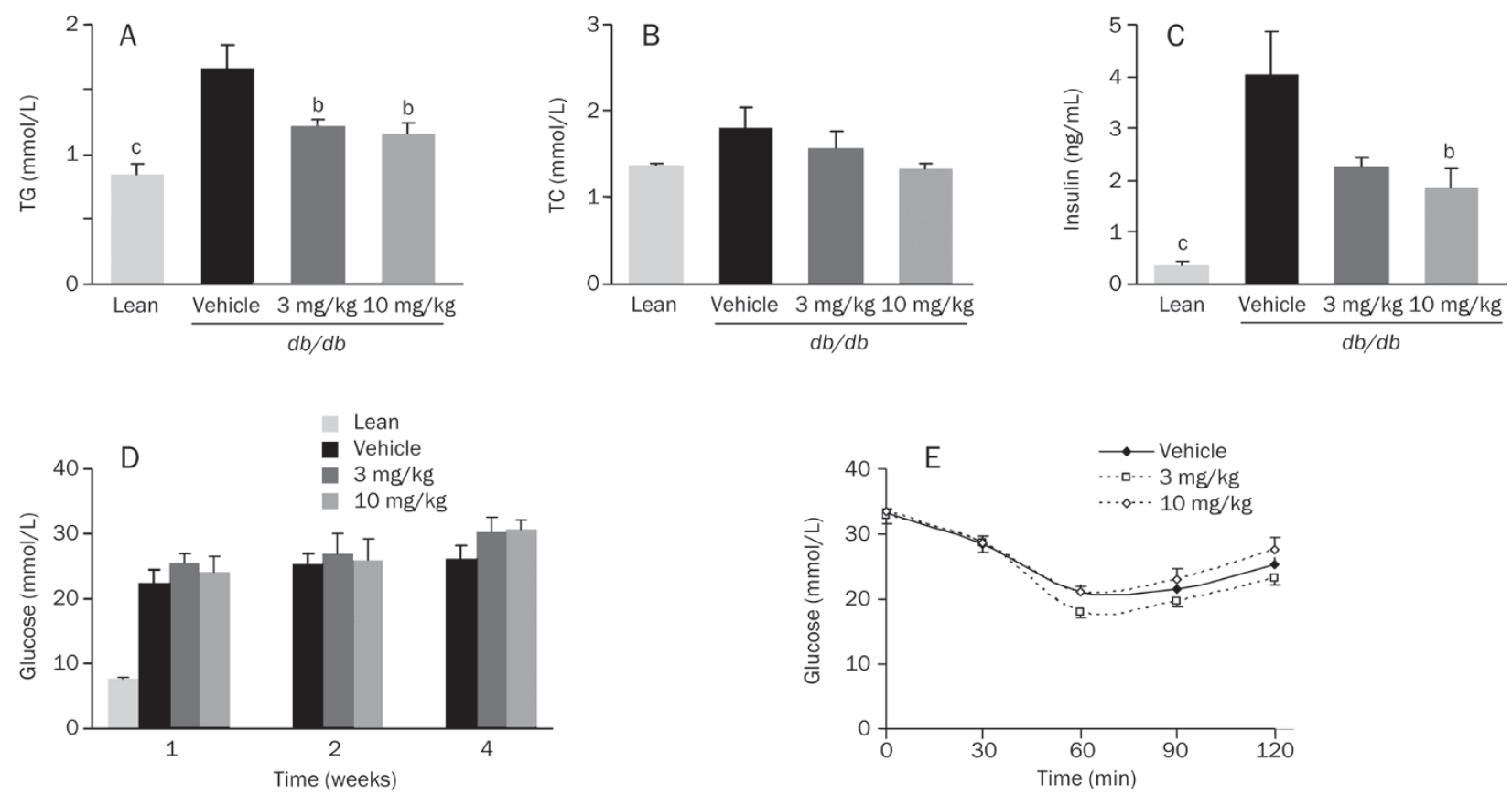

Figure 3. H128 treatment lowers blood lipids but did not change glucose metabolism in $d b / d b$ mice. Serum lipid and insulin levels were measured after $12 \mathrm{~h}$ fasting in $\mathrm{db} / \mathrm{db}$ mice treated with vehicle or $\mathrm{H} 128$ for 5 weeks. (A) Triglycerides, (B) total cholesterol (TC) and (C) insulin. (D) Six hour-fasted glucose levels were monitored after 1, 2, and 4 weeks of $\mathrm{H} 128$ treatment. (E) Insulin tolerance test was performed after 5 weeks of H128 treatment. All data are expressed as the mean \pm SEM. $n=5-6$. ${ }^{b} P<0.05,{ }^{c} P<0.01$ vs vehicle group.

damage. H128 treatment decreased the serum levels of ALT and AST, indicating a reversal of liver pathology (Figure 4D and 4E). These results indicate that H128 treatment protects against hepatic steatosis in $d b / d b$ mice.
Effects of $\mathrm{H} 128$ on the expression of genes related to hepatic lipid metabolism

To elucidate the molecular mechanisms by which inhibiting DGAT1 leads to protection against obesity and hepatic ste- 


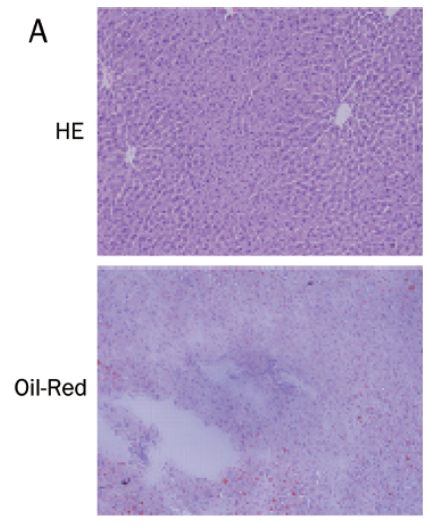

Lean

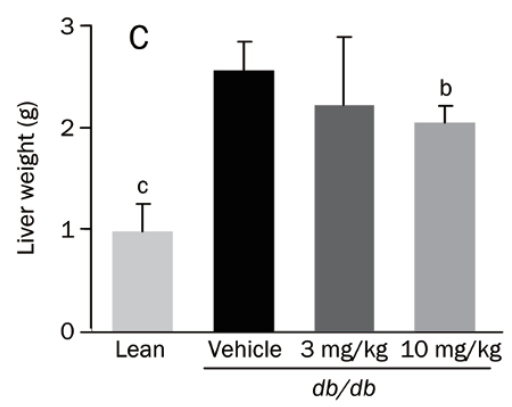

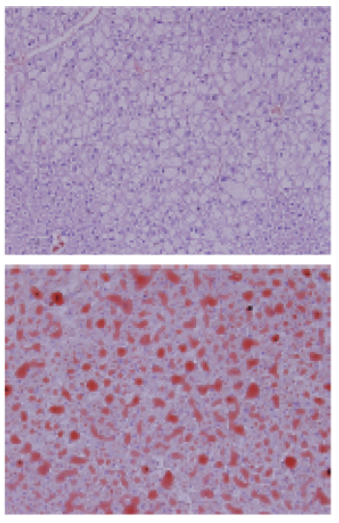

$d b / d b$-Vehicle

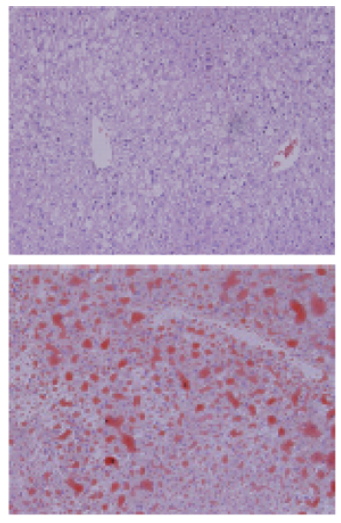

$\mathrm{db} / \mathrm{db}-10 \mathrm{mg} / \mathrm{kg}$
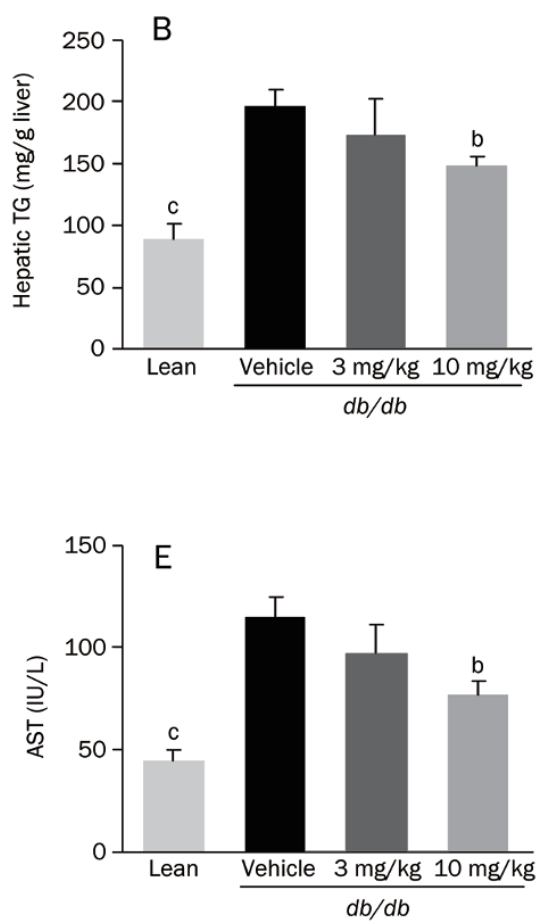

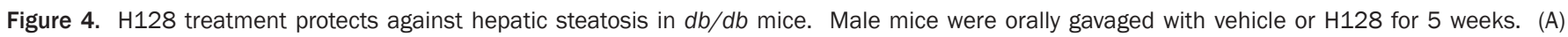

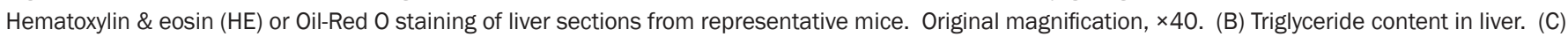
Liver weight. (D) Serum ALT level. (E) Serum AST level. All data are expressed as the mean \pm SEM. $n=5-6$. ${ }^{b} P<0.05$, ${ }^{c} P<0.01$ vs vehicle group.

atosis, we further examined the expression of genes involved in hepatic lipid metabolism in $d b / d b$ mice. Compared with the vehicle group, $\mathrm{H} 128$ treatment at $10 \mathrm{mg} / \mathrm{kg}$ significantly increased the levels of CPT1 and PPARa mRNAs (Figure 5E and $5 \mathrm{~F}$ ), both of which are key regulators of fatty acid oxidation in rodents ${ }^{[21]}$. However, no significant differences were detected in the levels of mRNAs encoding proteins related to fatty acid synthesis ${ }^{[22]}$, such as SCD1, ACC1, SREBP1c, and PPARY (Figure 5A-5D), implying that H128 treatment did not affect fatty acid synthesis in the liver of $d b / d b$ mice.

\section{Discussion}

In this study, we demonstrated for the first time that oral administration of H128, a small-molecule inhibitor of DGAT1, can reduce body weight gain, hyperlipidemia, and hepatic steatosis but does not improve glucose metabolism in $d b / d b$ mice. At the dose of $10 \mathrm{mg} / \mathrm{kg}, \mathrm{H} 128$ treatment significantly reduced body weight gain and food intake. Although H128 treatment at $3 \mathrm{mg} / \mathrm{kg}$ also decreased food intake, it did not significantly inhibit body weight gain. Thus, decreased food intake may not be enough for the beneficial effects of H128 treatment in $d b / d b$ mice.

The highest levels of DGAT1 expression are found in the small intestine, suggesting an important role for DGAT1 in intestinal triglyceride synthesis and dietary fat absorption ${ }^{[7,9]}$. In support of this notion, Dgat1 $1^{-/-}$mice exhibit a delay in circu- lating postprandial hypertriglyceridemia, suggesting a reduction of intestinal triglyceride absorption ${ }^{[23]}$. The importance of DGAT1 in dietary fat absorption has been further confirmed by potent DGAT1 inhibitors. For example, the DGAT1 inhibitor XP620 reduces apolipoprotein B secretion in Caco-2 cells, triglyceride synthesis in primary enterocytes and dietary fat absorption in normal Sprague-Dawley rats ${ }^{[24]}$. Moreover, new, potent DGAT1 inhibitors reduce dietary fat absorption following a lipid challenge and decrease body weight in DIO mice ${ }^{[18,19]}$, recapitulating the major phenotype of $D$ gat $1^{-/-}$mice. Our results show that the DGAT1 inhibitor H128 inhibited dietary fat absorption in $d b / d b$ mice, which may be a major reason for the beneficial effects of $\mathrm{H} 128$ treatment in $d b / d b$ mice.

Increased energy expenditure is believed to be one of the major reasons why $D g a t 1^{-/-}$mice are protected from dietinduced obesity ${ }^{[11,12,25]}$. In the present study, H128 treatment significantly increased hepatic levels of CPT1 and PPARa mRNAs in $d b / d b$ mice, indicating that $\mathrm{H} 128$ enhanced fatty acid oxidation. Actually, fatty acid oxidation in $D g a t 1^{-/-}$mice is also up-regulated ${ }^{[12]}$. Thus, our results are consistent with the increased energy expenditure in $D g a t 1^{-/-}$mice because enhanced fatty acid oxidation is assumed to increase energy expenditure ${ }^{[26,27]}$. The reason why inhibition of DGAT1 would enhance fatty acid oxidation remains unknown. Due to the increased leptin sensitivity in $\operatorname{Dgat1}^{-/-}$mice $^{[12]}$ and the positive effect of leptin on fatty acid oxidation ${ }^{[28,29]}$, DGAT1 may 
A

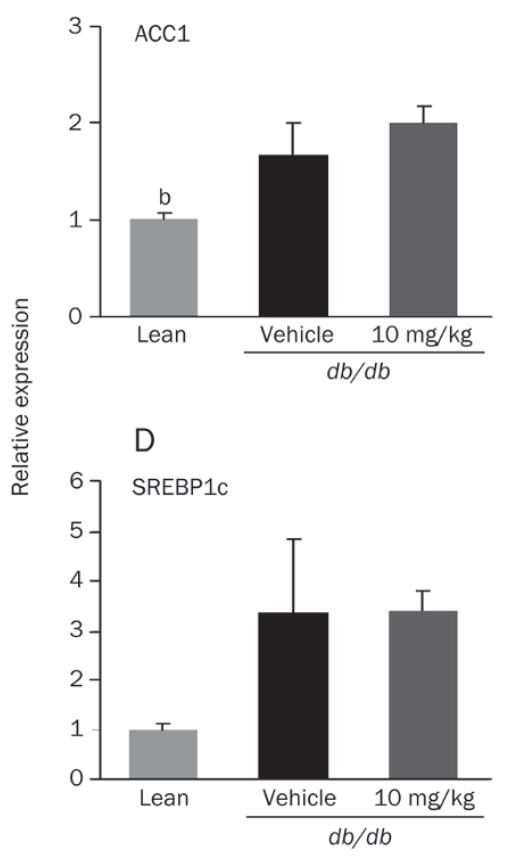

B

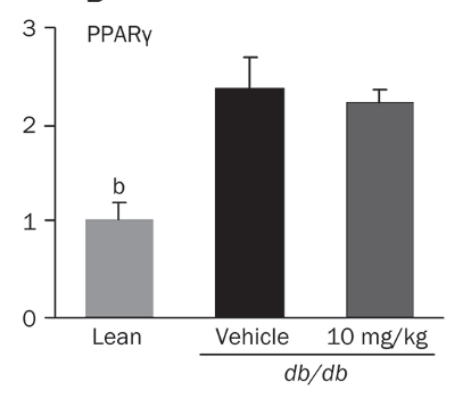

$\mathrm{E}$

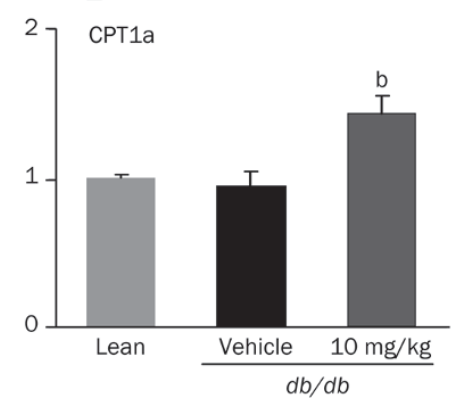

C

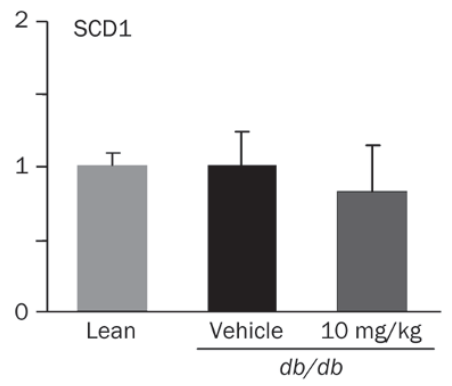

$\mathrm{F}$

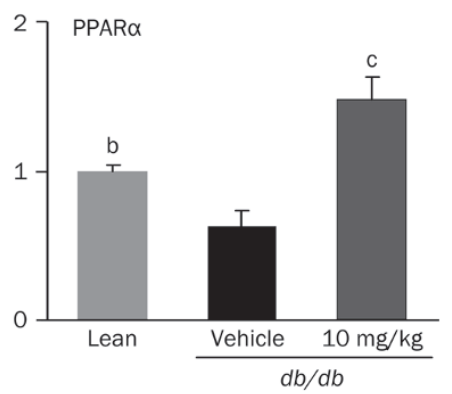

Figure 5. Effects of $\mathrm{H} 128$ on the expression of genes related to fatty acid regulation in liver. At the end of the experiment, total RNA was extracted from the liver, and semi-quantitative real-time PCR was performed to assess of the mRNA levels of the indicated genes involved in fatty acid regulation. (A) ACC1, acyl-CoA carboxylase 1. (B) PPAR $\gamma$, peroxisome proliferator-activated receptor gamma. (C) SCD1, stearoyl-CoA desaturase 1. (D) SREBP1c, sterol regulatory element binding protein 1c. (E) CPT1a, carnitine palmitoyltransferase 1a. (F) PPAR $\alpha$, peroxisome proliferator-activated receptor alpha. All data are expressed as the mean \pm SEM. $n=3 .{ }^{b} P<0.05,{ }^{c} P<0.01$ vs vehicle group.

regulate fatty acid oxidation via the leptin signaling pathway. However, the DGAT1 inhibitor H128 enhanced fatty acid oxidation in the leptin receptor-deficient $d b / d b$ mice, implying that leptin may be not necessary for DGAT1-regulated fatty acid oxidation.

DGAT1 is expressed highly in human liver ${ }^{[30]}$, and increased mRNA levels of DGAT1 have been found in humans with non-alcoholic fatty liver disease ${ }^{[31]}$, underscoring the importance of DGAT1 in hepatic steatosis. Global or liver-specific knockout of DGAT1 in mice protects them from diet-induced hepatic steatosis ${ }^{[13,15]}$. Likewise, pharmacological inhibition of DGAT1 decreases liver triglyceride content in DIO mice ${ }^{[15]}$. Nevertheless, liver-specific knockdown of DGAT1 in ob/ob or $d b / d b$ mice does not protect against hepatic steatosis ${ }^{[15]}$. Indeed, liver-specific knockdown of DGAT1 by intraperitoneal injection with antisense oligonucleotides is unable to diminish the effects of DGAT1 in extrahepatic tissues ${ }^{[15]}$. In the present study, H128 was administered by oral gavage, and it inhibited intestinal fat absorption and increased fatty acid oxidation, both of which may underlie the protective effect of H128 against hepatic steatosis in $d b / d b$ mice.

D gat $1^{-/-}$mice have increased sensitivity to insulin, and homozygous deletion of Dgat1 in $A^{Y} / a$ mice with insulin resistance and obesity significantly improves insulin sensitiv${ }^{i t y}{ }^{[12]}$. Therefore, it is appealing to speculate that pharmacological inhibition of DGAT1 by small-molecule inhibitors will improve glucose metabolism. However, H128 treatment for 5 weeks did not lower blood glucose or improve insulin toler- ance in $d b / d b$ mice. Hepatic steatosis is strongly associated with insulin resistance in animals and humans ${ }^{[32-34]}$. Although H128 treatment significantly improved hepatic steatosis, it did not improve glucose metabolism in $d b / d b$ mice. Of note, overexpressing DGAT1 in the liver of mice induces hepatic lipid accumulation and hepatic steatosis but does not impair glucose or insulin tolerance ${ }^{[35]}$. Also, it is possible that increased fatty acid oxidation by inhibition of DGAT1 may cause oxidation stress, leading to insulin resistance ${ }^{[36]}$, which neutralizes the effect of reduced triglycerides in liver. Thus, the increased insulin sensitivity in $\mathrm{Dgat1}^{-/-}$mice might be not attributable to decreased liver triglyceride content. A more likely explanation is that the effects of DGAT1 deficiency on glucose metabolism require an intact leptin pathway, because homozygous deletion of $D g a t 1$ in $d b / d b$ or leptin-deficient $o b / o b$ mice does not improve glucose metabolism ${ }^{[12]}$. On the other hand, the positive effects of H128 in $d b / d b$ models (such as reduced lipid absorption, reduced body weight gain, amelioration of hyperlipidemia and hepatic steatosis, and enhanced fatty acid oxidation) may be mediated in leptin-independent manners. Whether pharmacological inhibition of DGAT1 by small-molecule inhibitors can improve glucose metabolism needs further study in other animal models.

In conclusion, treatment with the DGAT1 inhibitor H128 reduced body weight gain, lowered blood lipids and improved hepatic steatosis in $d b / d b$ mice. Although H128 did not improve glucose metabolism in $d b / d b$ mice, we will further evaluate the effects of H128 on glucose metabolism in other 
animal models, such as DIO mice. Our findings suggest that inhibition of DGAT1 is an effective strategy to treat obesity, hyperlipidemia and hepatic steatosis.

\section{Acknowledgements}

This work was supported by Grant 2009ZX09301-001 from the National Science \& Technology Major Project "Key New Drug Creation and Manufacturing Program", by Grant 2007AA02Z301 from the National High Technology Research and Development Program of China (863 Program), by Grant 20972174 from the National Natural Science Foundation of China, by Grant 10410703900 from the Shanghai Committee of Science and Technology, by Grant 08431900800 from the Shanghai Science and Technology Innovation Program and by the Program for Professor of Special Appointment (Eastern Scholar) at Shanghai Institutions of Higher Learning.

\section{Author contribution}

He-yao WANG and You-hong HU designed the research; Xiao-dong ZHANG, Jian-wei YAN, Gui-rui YAN, Xiaoyun SUN, and Jun JI performed the experiments; Xiao-dong ZHANG analyzed the data; Xiao-dong ZHANG wrote the paper. Yi-ming LI was actively involved throughout the entire study.

\section{References}

1 LeRoith D. Dyslipidemia and glucose dysregulation in overweight and obese patients. Clin Cornerstone 2007; 8: 38-52.

2 Bray GA, Bellanger T. Epidemiology, trends, and morbidities of obesity and the metabolic syndrome. Endocrine 2006; 29: 109-17.

3 Heber D. An integrative view of obesity. Am J Clin Nutr 2010; 91: 280S-83S.

4 Chen HC, Farese RV Jr. Inhibition of triglyceride synthesis as a treatment strategy for obesity: lessons from DGAT1-deficient mice. Arterioscler Thromb Vasc Biol 2005; 25: 482-6.

5 Dickerson LM, Carek PJ. Pharmacotherapy for the obese patient. Prim Care 2009; 36: 407-15.

6 Buhman KK, Chen HC, Farese RV Jr. The enzymes of neutral lipid synthesis. J Biol Chem 2001; 276: 40369-72.

7 Cases S, Smith SJ, Zheng YW, Myers HM, Lear SR, Sande E, et al. Identification of a gene encoding an acyl CoA:diacylglycerol acyltransferase, a key enzyme in triacylglycerol synthesis. Proc Natl Acad Sci USA 1998; 95: 13018-23.

8 Cases S, Stone SJ, Zhou P, Yen E, Tow B, Lardizabal KD, et al. Cloning of DGAT2, a second mammalian diacylglycerol acyltransferase, and related family members. J Biol Chem 2001; 276: 38870-6.

9 Yen CL, Stone SJ, Koliwad S, Harris C, Farese RV Jr. Thematic review series: glycerolipids. DGAT enzymes and triacylglycerol biosynthesis. J Lipid Res 2008; 49: 2283-301.

10 Stone SJ, Myers HM, Watkins SM, Brown BE, Feingold KR, Elias PM, et al. Lipopenia and skin barrier abnormalities in DGAT2-deficient mice. J Biol Chem 2004; 279: 11767-76.

11 Chen HC, Ladha Z, Smith SJ, Farese RV Jr. Analysis of energy expenditure at different ambient temperatures in mice lacking DGAT1. Am J Physiol Endocrinol Metab 2003; 284: E213-8.

12 Chen HC, Smith SJ, Ladha Z, Jensen DR, Ferreira LD, Pulawa LK, et al. Increased insulin and leptin sensitivity in mice lacking acyl CoA:diacylglycerol acyltransferase 1. J Clin Invest 2002; 109: 1049-55.
13 Smith SJ, Cases S, Jensen DR, Chen HC, Sande E, Tow B, et al. Obesity resistance and multiple mechanisms of triglyceride synthesis in mice lacking Dgat. Nat Genet 2000; 25: 87-90.

14 Chen HC, Rao M, Sajan MP, Standaert M, Kanoh Y, Miura A, et al. Role of adipocyte-derived factors in enhancing insulin signaling in skeletal muscle and white adipose tissue of mice lacking Acyl CoA:diacylglycerol acyltransferase 1. Diabetes 2004; 53: 1445-51.

15 Villanueva CJ, Monetti M, Shih M, Zhou P, Watkins SM, Bhanot S, et al. Specific role for acyl CoA:Diacylglycerol acyltransferase 1 (Dgat1) in hepatic steatosis due to exogenous fatty acids. Hepatology 2009; 50: 434-42.

16 Matsuda D, Tomoda H. DGAT inhibitors for obesity. Curr Opin Investig Drugs 2007; 8: 836-41.

17 Chen HC, Farese RV Jr. DGAT and triglyceride synthesis: a new target for obesity treatment? Trends Cardiovasc Med 2000; 10: 188-92.

18 Birch AM, Birtles S, Buckett LK, Kemmitt PD, Smith GJ, Smith TJ, et al. Discovery of a potent, selective, and orally efficacious pyrimidinooxazinyl bicyclooctaneacetic acid diacylglycerol acyltransferase-1 inhibitor. J Med Chem 2009; 52: 1558-68.

19 Zhao G, Souers AJ, Voorbach M, Falls HD, Droz B, Brodjian S, et al. Validation of diacyl glycerolacyltransferase I as a novel target for the treatment of obesity and dyslipidemia using a potent and selective small molecule inhibitor. J Med Chem 2008; 51: 380-3.

20 Cool B, Zinker B, Chiou W, Kifle L, Cao N, Perham M, et al. Identification and characterization of a small molecule AMPK activator that treats key components of type 2 diabetes and the metabolic syndrome. Cell Metab 2006; 3: 403-16.

21 Goepfert S, Poirier Y. Beta-oxidation in fatty acid degradation and beyond. Curr Opin Plant Biol 2007; 10: 245-51.

22 Nakamura MT, Nara TY. Essential fatty acid synthesis and its regulation in mammals. Prostaglandins Leukot Essent Fatty Acids 2003; 68: 145-50.

23 Buhman KK, Smith SJ, Stone SJ, Repa JJ, Wong JS, Knapp FF Jr, et al. DGAT1 is not essential for intestinal triacylglycerol absorption or chylomicron synthesis. J Biol Chem 2002; 277: 25474-9.

24 Cheng D, lqbal J, Devenny J, Chu CH, Chen L, Dong J, et al. Acylation of acylglycerols by acyl coenzyme A:diacylglycerol acyltransferase 1 (DGAT1). Functional importance of DGAT1 in the intestinal fat absorption. J Biol Chem 2008; 283: 29802-11.

25 Shi Y, Cheng D. Beyond triglyceride synthesis: the dynamic functional roles of MGAT and DGAT enzymes in energy metabolism. Am J Physiol Endocrinol Metab 2009; 297: E10-8.

26 Thupari JN, Landree LE, Ronnett GV, Kuhajda FP. C75 increases peripheral energy utilization and fatty acid oxidation in diet-induced obesity. Proc Natl Acad Sci USA 2002; 99: 9498-502.

27 Bebernitz GR, Schuster HF. The impact of fatty acid oxidation on energy utilization: targets and therapy. Curr Pharm Des 2002; 8: 1199-227.

28 Minokoshi Y, Kim YB, Peroni OD, Fryer LG, Muller C, Carling D, et al. Leptin stimulates fatty-acid oxidation by activating AMP-activated protein kinase. Nature 2002; 415: 339-43.

29 Suzuki A, Okamoto S, Lee S, Saito K, Shiuchi T, Minokoshi Y. Leptin stimulates fatty acid oxidation and peroxisome proliferator-activated receptor alpha gene expression in mouse $\mathrm{C} 2 \mathrm{C} 12$ myoblasts by changing the subcellular localization of the alpha2 form of AMP-activated protein kinase. Mol Cell Biol 2007; 27: 4317-27.

30 Farese RV Jr, Cases S, Smith SJ. Triglyceride synthesis: insights from the cloning of diacylglycerol acyltransferase. Curr Opin Lipidol 2000; 11: 229-34.

31 Kohjima M, Enjoji M, Higuchi N, Kato M, Kotoh K, Yoshimoto T, et al. Re-evaluation of fatty acid metabolism-related gene expression in 
nonalcoholic fatty liver disease. Int J Mol Med 2007; 20: 351-8.

32 Marchesini G, Marzocchi R, Agostini F, Bugianesi E. Nonalcoholic fatty liver disease and the metabolic syndrome. Curr Opin Lipidol 2005; 16: 421-7.

33 Petersen KF, Shulman GI. Etiology of insulin resistance. Am J Med 2006; 119: S10-6.

34 Kelley DE, McKolanis TM, Hegazi RA, Kuller LH, Kalhan SC. Fatty liver in type 2 diabetes mellitus: relation to regional adiposity, fatty acids, and insulin resistance. Am J Physiol Endocrinol Metab 2003; 285: E906-16.

35 Monetti M, Levin MC, Watt MJ, Sajan MP, Marmor S, Hubbard BK, et al. Dissociation of hepatic steatosis and insulin resistance in mice overexpressing DGAT in the liver. Cell Metab 2007; 6: 69-78.

36 Shah S, Iqbal M, Karam J, Salifu M, McFarlane SI. Oxidative stress, glucose metabolism, and the prevention of type 2 diabetes: pathophysiological insights. Antioxid Redox Signal 2007; 9: 911-29 